\title{
ESPUMA NO COMBATE AOS INCÊNDIOS E SUA FITOTOXICIDADE NO CERRADO
}

\author{
Michel Aquino de Souza ${ }^{1}$ \\ Gustavo Dantas da Silva Emiliano ${ }^{2}$ \\ Pedro Henrique de Melo França ${ }^{3}$
}

\section{RESUMO}

O número de incêndios florestais e a área queimada aumentam acompanhando o aquecimento global e exigindo maior tecnificação do combate. Espuma de supressão impede a reignição, diminui a emissão de gases estufa, proporciona economia de água, bem como atenua o desgaste fisiológico dos combatentes. Restrições ambientais no cerrado têm impedido o uso de espumas no combate por carência de estudos garantidores da segurança ecológica. A fitotoxicidade é um possível risco ambiental das espumas. Portanto, objetivo deste trabalho é subsidiar a decisão do uso de espuma supressora e avaliar preliminarmente a fitotoxicidade de um protótipo de LGE para espécies nativas do cerrado. Para tanto, foi feita revisão de literatura e realizados testes de germinação, sobrevivência e desenvolvimento de árvore nativa em espuma.Depois de 98 dias, a solução com LGE a $2 \%$ levou a uma mortalidade de $15,8 \%$ das plântulas de Dalbergia miscolobium germinadas. São necessárias outras pesquisas ecotoxicológicas antes do uso de espuma no cerrado.

Palavras-chave: Espuma. Toxicidade. LGE. Incêndio. Dalbergia.

\footnotetext{
${ }^{1}$ Prof. Colégio Militar Dom Pedro II, CBMDF, Biólogo e Msc. C. Florestais, Email: prof.michel.cie@cmdpii.com.br.

2 Alunos da Iniciação Científica do Colégio Militar Dom Pedro II.

${ }^{3}$ Alunos da Iniciação Científica do Colégio Militar Dom Pedro II.
} 


\title{
FOAM IN FIGHTING FIRE AND ITS FITOTOXICITY IN
}

\section{SAVANNA}

\begin{abstract}
The number of forest fires and the area burned increase with global warming, requiring greater technification of combat. Suppression foams prevent reignition, reduce greenhouse gas emissions, provide water savings, and attenuate the physiological wear of firefighters. Environmental restrictions in the cerrado have impeded the use of foams in the fight for lack of studies that guarantee ecological safety. Phytotoxicity is a possible environmental risk of foams. Therefore, the objective of this work is to subsidize the decision to use suppressive foam and to evaluatepreliminarily the phytotoxicity of a prototype of LGE for native cerrado species. For this, tests were did of germination, survival and development of native tree. After 98 days, the solution with $2 \%$ LGE led to a $15.8 \%$ mortality of Dalbergia miscolobium seedlings germinated.Further ecotoxicological research is required prior to the use of foam in the cerrado.
\end{abstract}

Keywords: Dalbergia. Toxicity. Wildfire. Foamfire. Germination.

Artigo Recebido em 28/11/2019 e Aceito em 02/03/2020 


\section{INTRODUÇÃO}

Os incêndios florestais vêm aumentando acompanhando o aquecimento global com tendência de aumento no número de focos e da área queimada, exigindo o aperfeiçoamento das técnicas de combate (BARREIRO et al., 2010). Além dos problemas ambientais já causados pelos incêndios florestais com 140 mil focos detectados atingindo até $16 \%$ do cerrado anualmente (REZENDE, 2017), os gestores ambientais devem se preocupar com a potencial poluição causada pelo combate. Só os incêndios florestais em savanas tropicais emitem $1,66 \cdot 10^{15}$ toneladas de carbono para atmosfera anualmente, sem contar poluentes. (HOLEMANN, 1994). No entanto, as espumas supressoras podem diminuir a emissão desses gases.

São necessários mais estudos que garantam as vantagens da espuma no combate em cada bioma do Brasil de forma a assegurar a eficiência do uso do Líquido Gerador de Espuma (LGE) e a sua eficácia na extinção do fogo nas vegetações específicas brasileiras. Restrições ambientais no cerrado têm impedido o uso de espumas no combate aos incêndios por carência de estudos garantidores da segurança ecológica. Entre eles, a fitotoxicidade é um risco ambiental do LGE, poissupostamente ele pode impedir a renovação da vegetação afetando o ecossistema.

A crescente frequência e severidade dos incêndios florestais têm estimulado o aperfeiçoamento das técnicas de combate a incêndios a fim de diminuir a área afetada (COUTO-VA'ZQUEZ et al., 2011). A série histórica de atendimentos a incêndios florestais do Corpo de Bombeiros Militar do Distrito Federal revela cerca de 6.000 combates por ano (CBMDF, 2013), mas a estatística aponta também para um aumento na área queimada. Em 2016, foram 17.392 hectares, de área queimada no Distrito Federal. Já em 2017, foram 42.809 hectares queimados (MORAIS e MATRICARDI, 2018).

Entre os produtos disponíveis para ajudar no combate aos incêndios florestais, as espumas apresentam menor toxicidade em geral. Agentes 
espumantes são retardadores de fogo de ação rápida que tem seus efeitos de redução da inflamabilidade diminuídos após a evaporação da água. Dessa forma, espumas supressoras contra incêndios florestais vem sendo desenvolvidas para aumentam sobremaneira a eficiência e economia da água na extinção.(LARSON et al., 1999; SOARES e BATISTA, 2007; VOGELS et al., 2015). As pesquisas devem garantir ainda que o uso de espumas supressoras tem segurança ambiental e ergonômica efetivas.

Entre os impactos ecológicos das espumas supressoras de incêndios, algumas pesquisa sugerem que elas podem levar a declínios na riqueza de espécies (LARSON et al., 1999), reduzir as taxas de germinação de sementes (SONGet al., 2014), e causar mudanças a longo prazo nos ecossistemas soloplanta (COUTO-VA'ZQUEZ et al., 2011).

O objetivo deste trabalho é avaliar o uso da espuma no combate aos incêndios florestais a partir de uma revisão na literatura sobre seus aspectos técnicos, táticos e ambientais e analisar experimentalmente a fitotoxicidade de um protótipo de LGE para espécies nativas do bioma cerrado. Agora, passa-se a avaliação da eficiência operacional, da eficácia tática e efetividade estratégica das espumas supressoras, depois analisa-se a fitotoxicidade de um protótipo.

\section{REVISÃO DE LITERATURA}

A espuma é o produto gerado pela mistura do Líquido Gerador de Espuma (LGE) e da água num sistema proporcionador de espuma que injeta ar nessa solução. Basicamente o LGE é composto por um sabão, um surfactante e diluentes. Com isso, a espuma é formada por bolhas de ar que se mantêm devido ao tensoativo do LGE que diminui a tensão superficial da água. Sua capacidade de isolante térmico se deve à baixíssima condutividade térmica do ar 0,024 W/m.K (YOUNG, 1987). 


\section{Eficiência da espuma}

A água é o agente extintor universal utilizado para deter a propagação do fogo. Quando enriquecida com o LGE, são potencializadas suas características extintoras. O extrato de espuma promove um aumento significativo na capacidade de penetração nos combustíveis florestais reduzindo o risco de reignição. Segundo Soares(2000), a eficiência no combate é medida pela velocidade de extinção do incêndio, desde a ignição até o domínio do fogo. Nesse sentido, as espumas supressoras podem aumentar a eficiência do combate.

O número de ocorrências de combate aos incêndios vem crescendo no Distrito Federal, concentradas nos meses de junho a setembro de 10 às $19 \mathrm{~h}$. (CBMDF, 2017). Associado ao fenômeno climático El niño, o DF passou em 2017 por uma crise hídrica sem precedentes levando ao racionamento no fornecimento de água. Esse fenômeno conduziu ao aumento da área queimada que chegou a 43.088 hectares, a maior desde 1987 (SOUZA, 2017). Considerando que a economia pelo uso da espuma é de 624\% (Braga, 2014) equivale a um aumento a disponibilidade de água à população.

Em paralelo, a economia de água no combate com espuma promove mais eficiência visto que o combatente florestal se desloca menos tempo para reabastecer sua bomba. Nos combates no cerrado, os bombeiros se expõem a intensidade da frente de fogo de até $16.394 \mathrm{~kW} / \mathrm{m}$ com velocidade de até $2,2 \mathrm{~m} / \mathrm{s}$, em que 0 ar que pode chegar a $884^{\circ} \mathrm{C}$ (MIRANDA et al., 2010), condições críticas para o trabalho de bombeiros (BRAGA et al., 2016). Com a economia de água e menos deslocamentos para reabastecimento, o bombeiro emprega suas energias efetivamente no combate.

\section{Eficácia do LGE}

A espuma permite que a água absorva de forma mais eficaz o calor formando um fino filme de água que se espalha rapidamente sobre 0 combustívele tendo maior duração. Além disso, protege os combustíveis da 
ignição suprimindo vapores, mantendo o combustível molhado e isolado da chama, do calor e do oxigênio bem como refletindo o calor. Dessa forma, a água se mantém por mais tempo numa fina camada sobre o combustível, levando a menor emissão de gases da combustão (estufa e tóxicos) e aumentando a umidade relativa do ar na área de combate. (USDA, 1993). Por prevenir reignições, torna o trabalho do combate menos extenuante e mais seguro em ambientes de difícil acesso em que haja necessidade de constantes reabastecimentos.

Nesse sentido, a espuma atua nos três lados do triângulo do fogo: aumentando a aderência e a drenagem, mantendo a solução por mais tempo sobre o combustível, evitando o acesso do ar comburente e o fluxo de secagem do combustível. Isso prende a água vaporizada entre o combustível e a camada de espuma com efeito de abafamento, diminuindo a corrente de convecção e a irradiação propagadora do fogo, bem como a propagação por contato. Com a expansão do mesmo volume de água aumentado em 10x, a espuma pode formar uma espessa camada de proteção que reflete a irradiação das chamas adjacentes dispersada em todas as direções pela bolha refletora e isolante da espuma. (STECHISHEN, 1991).

O espumógeno On Seven é capaz de diminuir consideravelmente a reignição pois consegue resfriar o combustível até $10,3{ }^{\circ} \mathrm{C} / \mathrm{s}$, enquanto a água resfria, em média, $1,5^{\circ} \mathrm{C} / \mathrm{s}$. (AGUIAR, 2014). A efetividade da espuma foi testada por Anderson e McDonald (2015)em que amostras tratadas com espuma apresentaram um tempo de ignição das chamas após 340squando comparadas ao combustível tratado com água (180s).

$\mathrm{O}$ aceiro pode ser feito em faixas de espuma de 6 a $10 \mathrm{~m}$ de largura (USDAFS, 2007) sendo também indicada para alargar aceiros já existente ou como barreira para contenção das chamas (até $30 \mathrm{~min}$ ), evitando a evaporação da água e impedindo a reignição. (CASTRO, 2003). Entre outras vantagens da espuma, destaca-se a redução do tempo de supressão das chamas, facilidade de misturar, fornecimento de uma barreira contra incêndio em curto prazo e 
aumentodo teor de umidade no combustível em 50\%. O aceiro de água molhada também pode ser formado utilizando-se bomba costal. Neste caso a diluição do LGE deve ser de $0,2 \%$ a fim de garantir uma maior durabilidade da espuma assumindo um caráter protetivo e isolante contra propagação das chamas. (URBAS, 2012).

Dependendo da concentração do espumógeno na solução pode-se produzir vários tipos de espuma, conforme recomendação dos fabricantes. A água molhada é formada a partir da adição de $0,1 \%$ de LGE, garantindo uma alta penetração nos combustíveis florestais, podendo ser usada como agente extintor para incêndios subterrâneos,terrestres, de copae braseiros.(USDA, 1993).Principalmente a água molhada pode ser aplicada também por meio de aeronaves. Pode-se ainda utilizar a solução em maior concentração para proteção de estruturas próximas ao incêndio. (KALABOKIDIS, 2000).

A espuma molhada apresenta bolhas de ar imersas em grande quantidade de solução, que proporciona drenagem muito rápida e serve para ataque direto em combustíveis finos e secos. A espuma fluida apresenta maior quantidade de bolhas esféricas com algumas paredes em contato, o que proporciona uma boa drenagem sem formação de picos de espuma. Portanto, é adequada para ataque direto na maioria dos combustíveis e como proteção de árvores e de estruturas, bem como para aceiro de espuma por menos de 30 min. (USDA, 1993).

Já a espuma seca (geralmente $1 \%$ de LGE) apresenta grande quantidade de ar que caracteriza a alta capacidade de isolamento térmico. Ela apresenta-se como um creme com bolhas poliédricas pequenas e drenagem muito lenta, de modo que podem se formar picos para aderir a superfícies verticais. Portanto, serve para isolar o solo e combustíveis verticalizados com barreiras de espuma por mais de 30 min. (USDA, 1993).

A espuma pode ser produzida e aplicada através de vários equipamentos entre os quais destaca-se o CAFS(Compressed Air Foam System = sistema de espuma de ar comprimido). Além de poder ser utilizada 
com sistema CAFS,o misturador entre linhas com sistema de tubo de Venturi e/ ou um esguicho proporcionador de espuma podem ser utilizados. (NATIONAL FOAM, 2002). Stechishen (1991) avaliou o sistema CAFS como mais versátil e eficaz para produção de espuma pois pode produzir diversos tipos de espuma com concentração controlada, bolha menor, mais uniforme e duradoura, como espuma seca de alta qualidade. Enquanto o misturador com tubo de Venturi pode ser utilizado com eficácia só até espuma fluida.

Nas viaturas, o sistema gerador de espuma CAFS economiza $42 \%$ quando comparado ao sistema de venturi (DIMAT, 2013).Soares(2000) indica o uso de caminhonetes com 400 a 1000 litros de água e CAFS para os combates florestais devido a mobilidade desses veículos leves. Uma alternativa seria o emprego de CAFS portáteis com a possibilidade da instalação de um sistema proporcionador capaz de produzir 200L de espuma em motocicletas (AGUIAR, 2014).

O boletim técnico da mochila anti-incêndio prevê que ela pode ser utilizada com espumógeno e bico aerador para espuma. Também com água molhada utilizando o bico pulverizador que pode alcançar 12m. (GUARANY, 2016). O lubrificante do esguicho pulsátil deve ser resistente ao detergente do LGE e a altas temperaturas, além de ser atóxico.

Outra alternativa tática é a utilização da espuma em linhas de mangueira pressurizadas utilizando a moto-bomba Mark-3 ou assemelhada. Para essa tática, comumente empregada para combate de incêndios subterrâneos, o uso de misturador entre linhas é indicado. Especialmente em incêndios de maiores proporções e preferencialmente em localidades inclinadas (encosta/ barranco) pode-se utilizar a espuma de alta expansão para confecção de um aceiro de espuma com o uso de um ventilador proporcionador.

A queima controlada, seguindo critérios técnicos e a legislação correlata (Decreto 2661/98, Portaria IBAMA 94-N/98), pode ser mais seguramente aplicada se, a tática para esta operação incluir a espuma em 
linhas pressurizadas ou em bombas costais (SCHULER, 2015). Nos incêndios em instalações elétricas de até $35.000 \mathrm{~V}$ na interface urbano-florestal, pode-se aplicar espuma mantida a distância de segurança de 4m. (AGUIAR, 2014).

\section{Efetividade do uso do LGE}

Agora analisam-se as questões estratégicas dos impactos causados pelas espumas.

Suspeita-se de diversos impactos ambientais quando a solução de LGE se acumula no solo após evaporação. Salvo no caso de derramamentos acidentais, a aplicação operacional das diversas concentrações de LGE não são graves o suficiente em comparaçãoaos danos potenciais do incêndio florestal sobre a biodiversidade local. De modo geral, o LGE não leva a impactos ambientais significativos no solo, nos seus macro-invertebrados e na vegetação, possivelmente devido a rápida diluição das baixas concentrações de trabalho. Por causa da sua alta biodegradabilidade, não afeta significativamente as comunidades microbianas, de plantas, de invertebrados e vertebrados (VOGELS et al, 2015).

A toxicidade aponta para o efeito potencialmente danoso que um produto pode causar a um determinado organismo, dependendo da concentração e do tempo de exposição. Para toxicidade no solo, os testes de germinação são indicados pois se desenvolvem com uma série de eventos fisiológicos sensíveis a contaminações, para os quais se utiliza classicamente a Lactuca sativa por ser sensível a inibidores tóxicos (TAMADA et al., 2012; BRITO, 2014). Os surfactantes (tensoativos) da formulação do LGE diminuem a disponibilidade de oxigênio (HARTSKEERL et al., 2004) e as divisões celulares altamente requerentes de $\mathrm{O}_{2}$ podem ser prejudicadas impedindo a continuidade da germinação após o rompimento do tegumento e emergência da radícula. (EVERT et al., 2014).

Brito (2014) avaliou o potencial de toxicidade das cinzas e demonstrou que as águas superficiais foram intoxicadas pelas cinzas provenientes dos 
incêndios. Miranda (2013) demonstra que os incêndios florestais podem estar influenciando a dinâmica de nutrientes em pequenas drenagens em matas de galeria do Cerrado, principalmente pela incorporação das cinzas nos componentes do fluxo e da volatilização de partículas para atmosfera durante o incêndio. Dessa forma, entende-se que o incêndio em si já afeta as comunidades aquáticas mais sensíveis ao aumento de substâncias químicas das cinzas dissolvidas. Portanto, o uso de espuma no combate aos incêndios não é o único fator que pode intoxicar as espécies animais e vegetais de áreas nativas, pois as próprias cinzas geradas já causam danos ambientais.

Adams e Simmons (1999) concluíram que o uso de espumas supressoras tem um custo ecológico menor que os aceiros escavados ou capinados pois não suprimem a vegetação, apesar de constituírem riscos ambientais especialmente para os ecossistemas aquáticos australianos. Eles indicaram o combate aos incêndios com espumas para áreas de alto valor silvestre ou paisagístico, admoestando usos desnecessários. Adams et al. (2004) concluíram que o combate com espuma é menos prejudicial que as técnicas tradicionais de supressão das queimadas, constituindo-se como técnica eficaz para bombeiros.

Ao analisar os possíveis efeitos tóxicos de espumas, Finger et al.(1997) explica que evitar a aplicação de espumas é apropriado, pois ela pode causar mortandade de peixes em ecossistema aquático. Mas para ambientes terrestres não há contraindicação pelos testes que fizeram com plantas, invertebrados e vertebrados. Vogels et al. (2015) recomendam o uso de espumas após análise da toxicidade em laboratório e em campo apenas se a construção de aceiros e linhas molhadas não for possível ou desejável, se existe risco de descontrole do incêndio, o local está longe de águas superficiais e seja possível aplicar em pequenas superfícies.

Embora os impactos ecológicos terrestres sejam limitados e o influxo de águas subterrâneas contaminadas tenha muito baixo risco, há perigo de envenenamento de águas superficiais. Na prática, o risco é considerável 
quando os cursos d'água recebem mais de 200 litros de espuma. Já para o solo, são insignificantes as alterações nas propriedades químicas ou qualidades edáficas, sem efeitos acidificantes ou eutrofizantes. (VOGELS et al, 2015). Portanto, não se deve aplicar espuma em locais onde ela possa escoar para cursos d'água ou lagos. Deve-se evitar vazamentos das tubulações próximos a cursos d'água. Caso haja derramamento em corpos hídricos, a solução deverá ser drenada para tanques impermeáveis, relatar e observar em até 30 dias se haverá mortandade de peixes nas proximidades.

Em geral, os impactos do próprio incêndio são maiores que os potenciais danos causados pela espuma. 0 gestor ambiental de florestas de preservação ou unidades de conservação deve avaliar se naquele local em um determinado momento pode-se ou não utilizar a espuma considerando o risco de danos catastróficos (KALABOKIDIS, 2000). Seria prudente testar a germinação de sementes e a sensibilidade de mudas das principais espécies em suas áreas antes de aplicar espuma para evitar os efeitos negativos imprevistos. (USDAFS, 2007). Por apresentar efeito fertilizante, a espuma pode favorecer gramíneas exóticas em detrimento da vegetação nativa(FINGER et al., 1997).

Por tratar-se de produto destinado à proteção de floresta ou ecossistema, mas não ter a finalidade de alteração da fauna ou da flora, não pode ser considerado agrotóxico ou afim, não se submetendo, portanto, ao seu regramento (BRASIL, 1989).

Biodegradabilidade da espuma

Para garantir a continuidade do uso de espuma, ela deve ser biodegradável para que não fique no solo por muito tempo. Nesse sentido, a NFPA 1150/2004 normatiza que o concentrado de espuma deve ter um mínimo de $60 \%$ biodegradação em 42 dias. Além disso, trata da toxicidade para macroinvertebrados, peixes, anfíbios e mamíferos, pois espuma de combate pode ser levada para águas superficiais se dissolvendo e perturbando o acesso do 
oxigênio. (HOLEMANN, 1994). Zhang et al. (2012) estudaram a biodegradação de três espumas classe $\mathrm{A}$ e concluiu que são facilmente biodegradáveis em até 28 dias com taxas de $85 \%$ a $89 \%$.Segundo o fabricante, oLGE PHOS-CHEK WD-881 é altamente biodegradável com mais $85 \%$ se transformando em dióxido de carbono em 28 dias. A biodegradabilidade de On Seven foi de 95\% em 14 dias (VOGELS et al., 2015).

Cruz et al.(2013)apontam que os microrganismos dos solos naturalmente têm a capacidade de biodegradação de hidrocarbonetos, diminuindo a toxicidade do LGE. Eles propõem ensaios com microrganismos e sementes bioindicadores junto com dados químicos para avaliar a qualidade do solo afetado. Para isso, a observação do crescimento da raiz e do hipocótilo de plântulas pode indicar contaminação subletal também após a biodegradação do poluente.

Impactos nos ecossistemas aquáticos

Kawano et al. (2014) concluíram que a espuma à base de sabão ecológico tem menor impacto agudo tóxico sobre os biótopos aquático e semiaquáticos com representantes da fauna, flora e microrganismos japoneses, que espumas comerciais.

Brito(2014) observou que as cinzas representam toxicidade principalmente para organismos aquáticos e aumentam a acidez, da mesma forma que muitos agroquímicos e fertilizantes podem aumentar as concentrações de nitrato e eutrofizar corpos hídricos. Ele verificou que os líquidos percolados em cinzas de carvão são tóxicos para Daphnia similis e para Lactuca sativa, mas a toxicidade é consideravelmente diminuída quando o percolado é misturado ao solo. Porém, grandes volumes de chuva podem carrear cinzas para os corpos de água causando intoxicações ao zooplâncton.

Devido aos surfactantes adicionados na formulação e dependendo do tamanho de suas cadeias, o LGE reduz a tensão superficial da água e aumenta a permeabilidade da membrana plasmática das células das brânquias, inibindo 
o consumo de oxigênio. Isso pode levar ao envenenamento de animais aquáticos por substâncias dissolvidas na água como metais pesados. (VOGELS et al., 2015).

\section{Impactos na vegetação e fauna}

A vegetação pode ser afetada de várias maneiras pelo uso de espuma. A espuma pode dissolver o revestimento de cera das plantas diminuindo 0 controle da evapotranspiração (BACKERet al., 2004). Finger et al.(1997) submeteram uma pradaria de Dakota do Norte (EUA) a aplicação de espuma e observaram uma maior herbivoria, aumento no tamanho das folhas $e$ diminuição das brotações. Já em Nevada (EUA) a espuma diminuiu a abundância e a diversidade da vegetação ribeirinha. Dessa forma, indicaram que os efeitos da aplicação de espuma devem ser transitórios. Testes de toxicidade em mamíferos têm apresentado baixo risco agudo em via oral e dérmica, bem como baixa irritação cutânea e ocular. (USDAFS, 2007).Portanto, os animais podem fugir, as sementes podem até germinar, mas na fase de plântula é necessário um solo equilibrado para o estabelecimento da vegetação.

Apesar disso, as consequências dos incêndios são devastadoras. As queimadas em três anos subsequentes podem matar até $73 \%$ da vegetação de campo sujo, principalmente plântulas, impedindo a sucessão ecológica. (MEDEIROS e MIRANDA, 2005). As queimadas no cerrado por si já causam alterações na fauna de insetos e mamíferos (MIRANDA, 2010).

\section{MATERIAL E MÉTODOS}

Foram testadas a germinação, sobrevivência e estabelecimento de plantas na presença de solução contendo um LGE protótipo a fim de avaliar a fitotoxicidade para vegetação do cerrado. O LGE deste estudo é composto por: Propileno glicol, Lauril éter sulfato de sódio, Ácido sulfônico, Amida 60, 
polissacarídeo Goma Xantana, Glicerina, Ureia, Hidróxido de Sódio e corante (BARROS, 2018, informação pessoal da formulação do LGE).

Coletou-se Latossolo vermelho-amarelo dos $10 \mathrm{~cm}$ superficiais retirando-sea camada de vegetação e palha superficialem cerrado típico localizado nas coordenadas $15^{\circ} 53^{\prime} \mathrm{S}, 47^{\circ} 56^{\prime} \mathrm{O}$. Portanto, esse solo manteve representatividade da sua biologia. Devido as condições de viveiro com irrigação diária, optou-se por adicionar areia lavada média no substrato de cultivo a fim de manter a permeabilidade, pois há uma tendência de compactação do latossolo.No período dos ensaios em Brasília (abril a agosto de 2018), a temperatura variou entre $10^{\circ}$ e $30^{\circ} \mathrm{C}$, com umidade relativa entre 20 e $80 \%$ (www.inmet.gov.br).

A avaliação da germinação e crescimento inicial de Lactuca sativa constituem-se como prova da toxicidade aguda (120h de exposição) representativa para plântulas em geral.As sementes de Lactuca sativa são indicadas para ensaios de germinação e fitotoxicidade pois são representativas da maioria das plantas.O ensaio de toxicidade aguda foi conduzido com sementes de Lactuca sativacom metodologia adaptada. (SOBRERO e RONCO, 2004).

A baixa fitotoxicidade é observada quando há emissão da radícula sem crescimento, pois substâncias tóxicas podem interferir nos numerosos processos fisiológicos desta fase alterando o desenvolvimento e a sobrevivência. O crescimento da radícula e do hipocótilo indicam a capacidade de estabelecimento e desenvolvimento e são muito sensíveis a substâncias tóxicas em concentrações baixas que não impediram a germinação. Isso se constitui como indicador subletal(SOBRERO e RONCO, 2004), caracterizado pela embebição, metabolismo, divisão celular, emergência da radícula, porém sem crescimento(EVERT et al., 2014).

Para avaliar o potencial tóxico sobre a flora do cerrado, foram feitos testes laboratoriais de germinação de Lactuca sativa em soluções contendo LGE e água destilada para o controle. As sementes foram dispostas sobre 
papel filtro analítico $80 \mathrm{~g} / \mathrm{m}^{2}$ em placas de Petri de $5 \mathrm{~cm}$ de diâmetro. O primeiro bioensaio de toxicidade aguda estática foi com $3 \mathrm{~mL}$ da solução de LGE a $2 \%$ em 10 sementes para cada placa de petri, com 10 repetições. O $2^{\circ}$ ensaio consistiu em $3 \mathrm{~mL}$ da solução com 1\% de LGE, 20 sementes em cada placa de Petri e 5 repetições. Em ambos, o controle consistiu em 100 sementes com água destilada. As placas de petri foram mantidas fechadas envoltas em plástico para evitar a desidratação sob temperatura e luz ambiente. A avaliação foi realizada após 5 dias.

Para análise de campo da fitotoxicidade sobre o banco de sementes, germinação, estabelecimento e desenvolvimento de plantas nativas, foram coletadas sementes de Dalbergia miscolobiumem $16^{\circ} 02^{\prime} \mathrm{S}, 47^{\circ} 57^{\prime} \mathrm{O} . D$. miscolobium é uma árvore representativa do cerrado típico e de campos, bem como dos seus bancos de sementes, que apresenta baixa germinação (BRAGIOLA, 2016).Silva et al.(2012) observaram que as sementes de $D$. miscolobium apresentaram germinação de até $82 \%$ de 5 a 25 dias e que podem suportar estresse térmico e hídrico com maior sobrevivência em ambientes abertos. Isso faz dela um bom indicador de germinação para campos e cerrado típico.

O ensaio de toxicidade crônica foi conduzido com Dalbergia miscolobium, seguindo uma abordagem escalonada de concentrações de exposição. (VOGELS et al., 2015). Três sementes foram plantadas em cada saco plástico de $800 \mathrm{~mL}$ para cultivo de mudas. Esses foram enchidos com três partes de Latossolo vermelho-amarelo coletado em $15^{\circ} 53^{\prime} \mathrm{S}, 47^{\circ} 56^{\prime} \mathrm{O}$ e uma parte de areia lavada para manter a permeabilidade.

Após a semeadura, foi feita a aplicação de $100 \mathrm{~mL}$ de solução LGE a $2 \%$ para cada saquinho com aproximadamente $0,01 \mathrm{~m}^{2}$ de área superficial de solo. Dessa forma,a aplicação consistiu de $200 \mathrm{~mL}$ de LGE por $\mathrm{m}^{2}$ de solo.Song et al., 2014, utilizaram a aplicação de $1 \mathrm{~L}$ de solução LGE a 1\%por $\mathrm{m}^{2}$ de solo, o que equivale a $10 \mathrm{~mL}$ de LGE por $\mathrm{m}^{2}$. Trinta e um sacos foram irrigados com $100 \mathrm{~mL}$ de solução LGE a $2 \%$ e 33 sacos do controle foram irrigados com 
$100 \mathrm{~mL}$ de água tratada.O experimento foi conduzido em viveiro com sombrite 50\% e micro-irrigação diária. A germinação foi avaliada semanalmente por 42 dias. Depois, passou-se a observação da sobrevivência, estabelecimento e desenvolvimento por mais 63 dias.

Para análise da toxicidade, utilizou-se osparâmetros de inibição:maior que $40 \%$ a solução é considerada tóxica; de $10 \%$ a $40 \%$, baixa toxicidade; menor que 10\%, não tóxico(ABBOT, 1925; TAMADA et al., 2012).

\section{RESULTADOS E DISCUSSÃO}

Consultando a Resolução CONAMA 420/2009 que trata dos valores referenciais para substâncias químicas potencialmente contaminantes, Lista de valores orientadores para solos e águas subterrâneas, não se encontram substâncias que compõem o LGE protótipo. O Nitrato (que pode ser biotransformado da Ureia por bactérias do solo) encontra-se na referida lista, mas não se atribui contaminação do solo, apenas para águas subterrâneas com o limite estabelecido em $10.000 \mu \mathrm{g} / \mathrm{L}$. Kawahara et al. (2016) propuseram um novo LGE a base de sabão ecológico Laurato de potássio e Oleato de potássio para combate a incêndios florestaisjaponeses. Como quelante,formularam o Ácido Metil Glicino Diacético como alternativa ao ácido sulfônico. Água, propilenoglicol e xilenoglicol foram utilizados como diluentes.

L. sativa apresentou $100 \%$ de germinação nos ensaios de controle em água destilada. Ela apresentou apenas emergência da radícula para ambos os ensaios com LGE, a $2 \%$ e 1\%. Portanto, apresentou uma inibição de 100\% para o alongamento do hipocótilo. Para LGE a $2 \%$, as radículas apresentaram em média $1 \mathrm{~mm}$, enquanto a $1 \%$, aproximadamente $2 \mathrm{~mm}$. A emergência da radícula de $L$. sativa indica que houve passagem da solução através do tegumento da semente, embebição do endosperma e ativação do crescimento embrionário. Porém, as células embrionárias entraram em contato direto com substâncias que causaram a fitotoxicidade aguda subletal para essas 
concentrações de LGE. Isso aponta para necessidade de alterações na composição do protótipo de LGE avaliado.

O tempo de germinação da maioria de $D$. miscolobium foi de 21 a 35 dias, mas com algumas germinando até 75 dias sem LGE. A taxa de germinação foi de $36,56 \%$ no substrato que recebeu a solução com LGE a $2 \%$, enquanto o controle apresentou $41,41 \%$ de germinação. Portanto, a solução com LGE inibiu a germinação em 4,85\% até o 35으 dia. Bragiola (2016) observou germinação de 30 a $84 \%$ das sementes de D. miscolobium em condições laboratoriais. Portanto, os resultados de germinação apresentam-se dentro de limites aceitáveis mesmo quando as sementes tiveram contato com o LGE.

O desenvolvimento da plântula em ambos os tratamentos apresentou em média 2 folhas (com desvio-padrão de 0,87 com LGE a 2\% e 0,97 sem LGE). As plântulas de $D$. miscolobium desenvolveram em média 8 folíolos com LGE a 2\% e 13 sem LGE.A Análise da variação pelo teste de $T$ da quantidade de folíolos no substrato com e sem espuma resultou em $p=0,1098$, indicando que os tratamentos não são significativamente diferentes. Depois de germinadas, houve uma mortalidade de $50 \%$ para as que receberam LGE e $34,2 \%$ para plântulas sem LGE. Portanto, a solução com LGE a $2 \%$ levou a uma mortalidade de $15,8 \%$ das plântulas germinadas depois de 98 dias, nas condições deste estudo. $\mathrm{O}$ experimento com $D$. miscolobium demonstrou baixa toxicidade, apesar da alta concentração da solução. Isso provavelmente se deve a alta biodegradabilidade do composto LGE pela microbiota e da dispersão da solução no solo. 
Revista Científica do Corpo de Bombeiros Militar de Pernambuco

Artigo Publicado no Vol.06 N.15 - Edição Jan a Jun 2020 - ISSN 2359-4829

Versão on-line disponível em: $\underline{\text { http://www.revistaflammae.com }}$

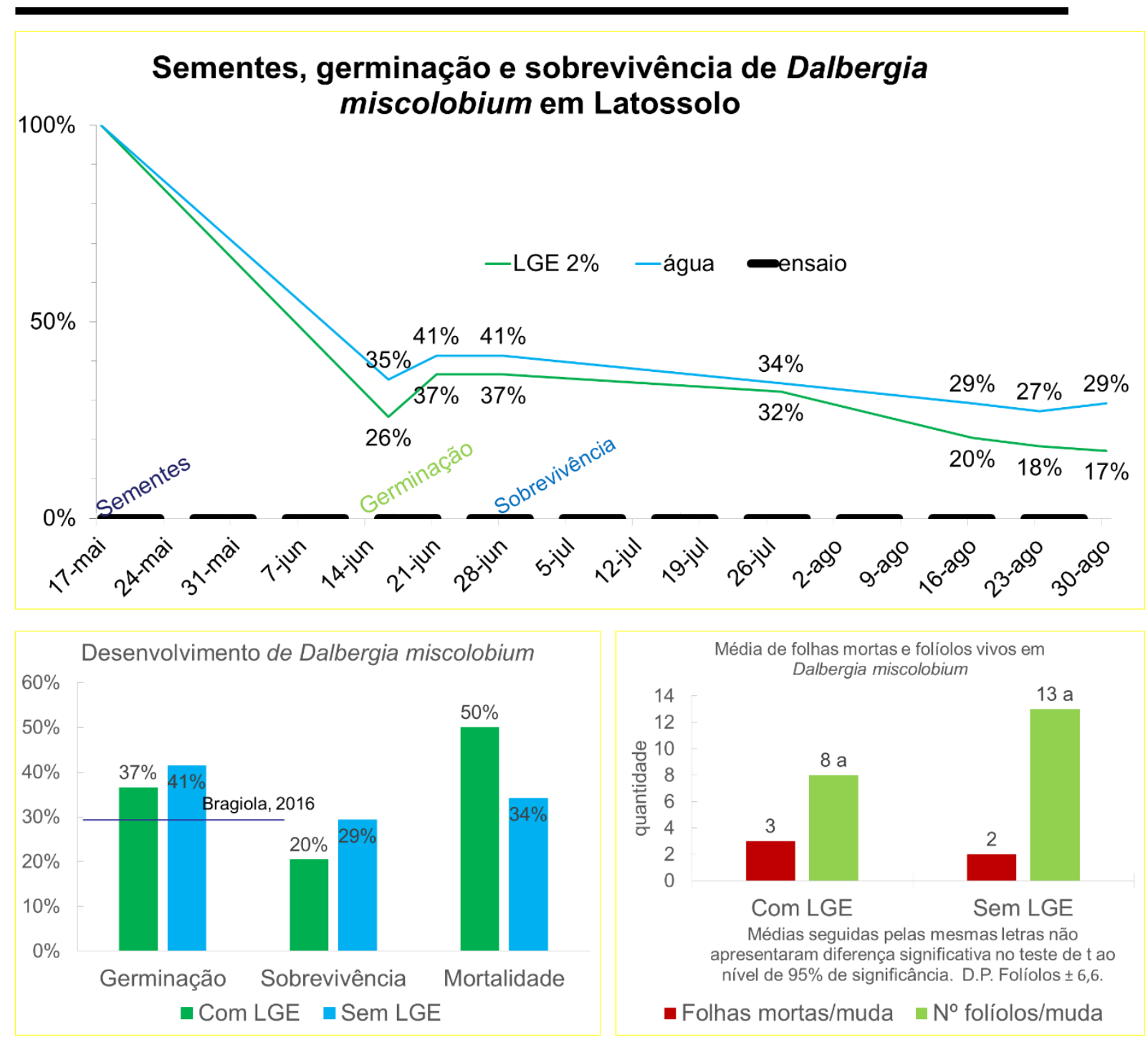

Figura 1. Gráficos dos resultados.

A queimada naturalmente afeta o banco de sementes, uma vez que aumenta a abundância de gramíneas em detrimento das dicotiledôneas (ANDRADE e MIRANDA, 2010), portanto, o impacto da baixa fitotoxicidade da espuma torna-se mais aceitável. Adams et al.(2004) considerando as espumas como uma ferramenta eficaz no combate a incêndios florestais, aplicaram espuma em mudas de sete espécies de plantas australianas, e não detectaram impactos no crescimento vegetativo. Hartskeerl et al. (2004) não observaram impactos severos ou de longo prazo para espécies nativas das savanas 
australianas, concluindo com o encorajamento para o uso de espumas supressoras.

\section{CONCLUSÕES}

O emprego da espuma aumenta a eficiência, eficácia e efetividade na supressão de incêndios florestais, contribuindo técnica, tática e estrategicamente.

O protótipo de LGE apresentou baixa fitotoxicidade para $D$. miscolobium representativa para os campo sujo e cerrado típico.

Considerando o amplo conhecimento mundial publicado e o crescente uso da tecnologia de combate a incêndios florestais com espuma, sugere-se a adoção de práticas que visem efetivar essas técnicas de combate nos corpos de bombeiros do Brasil. Mas, para garantir a segurança ergonômica, ambiental e econômica são necessárias outras pesquisas.

\section{RECOMENDAÇÕES}

Muitas operações de combate florestal têm alta carga deretrabalho. $O$ uso de LGE aumenta sobremaneira a efetividade da extinção, ao passo que torna improvável a reignição. Dessa forma, contribuindo para redução dos impactos ambientais, sociais e econômicos dos incêndios. Paralelo a isso, a atuação vem mostrando a necessidade de classificar as ocorrências também como incêndios de interface urbano-florestal. Visto que o LGE já é utilizado nos combates estruturais, o uso da espuma é recomendado em áreas antropizadas e/ou degradadas na interface urbano-florestal, distantes ao menos $100 \mathrm{~m}$ de cursos de água, fora de Áreas de Preservação Permanentes e fora de Unidades de Conservação. 
O que têm restringido o uso do LGE nos incêndios no cerrado é a preocupação quanto ao possível efeito tóxico sobre o ecossistema. Embora, os benefícios do uso desses LGEs para proteger as plantas em ecossistemas florestais ameaçados por incêndios de alta intensidade e rápida propagação superem os riscos menores da baixa toxicidade. Visto que o próprio incêndio no cerrado já traz toxicidade para ecossistemas, isso torna plausível o uso de espumas que podem até ter uma baixa toxicidade, mas que evitam um mal maior.

Por toda literatura científica citada, observa-se a viabilidade operacional e ambiental do uso das espumas nos incêndios em áreas urbanas e da interface urbano-rural/florestal. No entanto, em vegetação terrestre protegidas como Área de Preservação Permanente (APP) e Unidades de Conservação, o uso de espuma supressora poderá ser recomendado após pesquisas que assegurem que a toxicidade para os ecossistemas do bioma cerrado é aceitável, segundo os parâmetros estabelecidos pelo CONAMA (Conselho Nacional de Meio Ambiente) nas resoluções afetas ao tema. Nesse sentido, os relatórios de incêndios florestais devem descrever a localização e a quantidade de LGE utilizado para alimentar pesquisas futuras.

\section{REFERÊNCIAS}

ABBOTT, Walter S. et al. A method of computing the effectiveness of an insecticide. J. econ. Entomol, v. 18, n. 2, p. 265-267, 1925.

ADAMS, R.; SIMMONS, D. Ecological effects of fire fighting foams and retardants: a summary. Australian Forestry, v. 62, n. 4, p. 307-314, 1999.

ADAMS, Robyn et al. Surviving suppression: no detectable impacts of Class A foam on soil invertebrates and some Australian native plants. In: Bushfire 2004: earth, wind \& fire: fusing the elements: conference proceedings. 
Department for Environment and Heritage, South Australia, 2004.

AGUIAR, P. H. V. Vantagens do uso de espuma no combate a incêndios classe A, no âmbito do Corpo de Bombeiros Militar do Estado de Goiás. Curso Formação de Oficiais, Goiânia, 2014.

ANDERSON, S. A.; MCDONALD, A. G. Performance testing of wildland fire chemicals using a custom-built heat flux sensor. Journal of Fire Sciences, $v$. 33, n. 6, p. 473-492, 2015.

ANDRADE, LAZ de; MIRANDA, H. S. O fator fogo no banco de sementes. MIRANDA, HS Org. Efeitos do fogo sobre a estrutura de comunidades de Cerrado: resultados do Projeto Fogo. Brasília: IBAMA, p. 103-119, 2010.

BACKER, Dana M.; JENSEN, Sara E.; MCPHERSON, Guy R. Impacts of fire-suppression activities on natural communities. Conservation Biology, v. 18, n. 4, p. 937-946, 2004.

BARREIRO, A. et al. Response of soil microbial communities to fire and firefighting chemicals. Science of the total environment, v. 408 , n. 24, p. $6172-$ 6178, 2010.

BRAGA, G. C. B. A pesquisa em combate a incêndio realizada pelo CBMDF. (Apresentação de Trabalho/Seminário).2014.

BRAGA, G. C.; NETO, J.P.L.; SALAZAR, H. F. A Temperatura e Fluxo de Calor em uma situação de Incêndio e as consequências para os Bombeiros. Revista FLAMMAE. v. 2, n. 04, p. 9-28, 2016.

BRAGIOLA, N. G. Germinação, morfometria e qualidade ecológica em matrizes de Dalbergia miscolobium BENTH. Dissertação (Mestrado em Qualidade Ambiental). U.F. Uberlândia, 2016.

BRASIL, 1989, Lei no 7.802, de 11 de julho de 1989. Dispõe sobreagrotóxicos, seus componentes e afins. Disponível em: http://www.planalto.gov.br/ccivil 03/Leis/L7802.htm, acesso: 30/07/2018.

BRITO, Darlan Quinta de. Avaliação ecotoxicológica das cinzas de queimadas do Cerrado em ambientes aquáticos. Dissertação (Mestrado em Meio Ambiente e Desenvolvimento Rural)Universidade de Brasília, 2014. 
CASTRO, F. C. et al. Combate a Incêndios Florestais. Escola Nacional de Bombeiros, Manual de Formação Inicial de Bombeiro V. 13, 2를. Sintra. 2003.

CBMDF. Anuário estatístico de atendimentos do ano de 2016. Brasília, 2017.

2013.

. Anuário estatístico do Corpo de Bombeiros Militar do DF.Brasília,

COUTO-VÁZQUEZ, A.; GARCÍA-MARCO, S.; GONZÁLEZ-PRIETO, S. J. Long-term effects of fire and three firefighting chemicals on a soil-plant system. International Journal of Wildland Fire, v. 20, n. 7, p. 856-865, 2011.

CRUZ, J. M.; LOPES, P. R. M.; MONTAGNOLLI, R. N.; TAMADA, I. S.; SILVA, N. M. M. G.; BIDOIA, E. D.. 2013. Phytotoxicity of soil contaminated with petroleum derivatives and biodiesel. Ecotoxicol. Environ. Contam., v. 8, n.1, p. 49-54.

MEDEIROS, Marcelo B.; MIRANDA, Heloísa S. Mortalidade pós-fogo em espécies lenhosas de campo sujo submetido a três queimadas prescritas anuais. Acta bot. bras. 19(3): 493-500. 2005.

DIMAT. Termo de referência no 006/2013 DIMAT, anexo 1 do Edital de licitação de pregão eletrônico n.ำ 11/2013-DICOA/DEALF/CBMDF. 2013.

EVERT, R. F.;EICHHORN, S. E. Raven | Biologia vegetal. Revisão técnica Jane Elizabeth Kraus; tradução Ana Claudia M. Vieira. [et.al.]. - 8. ed. - Rio de Janeiro: Guanabara Koogan, 2014.

FINGER, Susan et al. Toxicity of fire retardant and foam suppressant chemicals to plant and animal.Edited by: USDI/US Geological Survey, Columbia, MO, 1997.

GUARANY, Indústria e Comércio Ltda. Boletim Técnico 1167.01. Mochila Costal Antiincêndio 21e. Fevereiro/2016, Vers. 02.Disponível em:www.guaranyind.com.br, acesso: 06/06/2016.

HARTSKEERL, K.; SIMMONS, D.; ADAMS, R. Does firefighting foam affect the growth of some Australian native plants?. International Journal of Wildland Fire, v. 13, n. 3, p. 335-341, 2004. 
HOLEMANN, H. A. N. S. Environmental problems caused by fires and firefighting agents. Fire Safety Science, v. 4, p. 61-77, 1994.

KALABOKIDIS, Kostas D. et al. Effects of wildfire suppression chemicals on people and the environment-a review. Global Nest: The International Journal, v. 2, n. 2, p. 129-137, 2000.

KAWAHARA, Takayoshi et al. Development of eco-friendly soap-based firefighting foam for forest fire. Environmental Control in Biology, v. 54, n. 1, p. $75-78,2016$.

KAWANO, T. et al. Eco-toxicological evaluation of fire-fighting foams in smallsized aquatic and semi-aquatic biotopes. In: Advanced Materials Research. Trans Tech Publications, 2014.

LARSON, D. L. et al. Effects of fire retardant chemicals and fire suppressant foam on vegetation in a North Dakota prairie. Proceedings of the North Dakota Academy of Science, v. 50, p. 137-144, 1996.In: Final Report. Interagency Fire Coordination Committee Boise, Idaho

MIRANDA, Fábio dos Santos. Características físico-químicas de pequenas drenagens em matas de galeria de cerrado após a ocorrência de incêndio florestal. Dissertação (Mestrado em Ecologia)Universidade de Brasília, Brasília, 2013.

MIRANDA, H. S. Efeitos do regime do fogo sobre a estrutura de comunidades de cerrado: resultados do projeto Fogo. Brasília-DF, Ibama, 2010.

MORAIS, P. P.; MATRICARDI, E.A.T. Análise espacialmente explícita dos incêndios florestais no Distrito Federal entre 1987 e 2017. Relatório do Curso de Eng. Florestal (UnB). 2018.

National Foam Fighting, Kidde Fire. A Fire Fighter's Guide to Foam. FFGUIDE01.PMD. 2002.

NFPA National Fire Protection Association. NFPA 1150 Standard on Foam Chemicals for Fires in Class A Fuels. Quincy: Secretary, Standards Council of NFPA, (2004). 
PHOS-CHEK.Phos-Chek® Wd-881 Class A Foam Fact Sheet. Disponível em:www.phos-chek.com, acesso: 20/08/2016.

RESENDE, Fernanda Cristina. Análise da distribuição espacial das áreas queimadas na porção nordeste do bioma cerrado. Dissertação Pós-Grad. em Geografia, U. F. São João del-Rei. 2017.

SCHULER, Hanna Ramella. Manejo do fogo em formações savânicas para redução de gases de efeito estufa: análise comparativa entre Austrália e Brasil. 2017.

SILVA, C. J.; SOUZA, M. A.; MARTINS, R. C. C. Análise da viabilidade e germinação de sementes de Dalbergia miscolobium Benth como alternativa para recuperação de áreas degradadas. VII Simpósio de Pós-Graduação em Ciências Florestais. VIÇOSA/MG - 17 a 19.set. 2012

SOARES, R. V. Novas tendências no controle de incêndios florestais. Floresta, v. 30, n. $12,2000$.

SOARES, Ronaldo Viana; BATISTA, Antônio C. Incêndios florestais: controle, efeitos e uso do fogo. Universidade Federal do Paraná, 2007.

SOBRERO, Maria Cecilia; RONCO, Alicia. Ensayo de toxicidad aguda con semillas de lechuga (Lactuca sativa L.). Ensayos toxicológicos y métodos de evaluación de calidad de aguas. IDRC/IMTA. Canadá, Capítulo, v. 4, p. 71-79, 2004. In: SÁNCHEZ-BAIN, Andrés et al. Ensayos toxicológicos y métodos de evaluación de calidad de aguas: estandarización, intercalibración, resultados y aplicaciones. CIID, Ottawa, ON, CA, 2004.

SONG, U. et al. Effects of three fire-suppressant foams on the germination and physiological responses of plants. Environmental management, v. 54, n. 4, p. 865-874, 2014.

SOUZA, Yanara Ferreira de. Incêndios florestais no Distrito Federal entre 1987 e 2017. Trabalho de conclusão de Bacharelado em Engenharia Florestal.Universidade de Brasília, Brasília, 2017.

STECHISHEN, Edward et al. The effectiveness of forest fire-fighting foams. PNFI, 1991.

TAMADA, Ivo S. et al. Toxicological evaluation of vegetable oils and biodiesel in 
soil during the biodegradation process. Brazilian Journal of Microbiology, v. 43, n. 4, p. 1576-1581, 2012.

United States Department of Agriculture (USDA). United States Department of Interior. National Association of State Foresters. National Wildfire Coordinating Group. Foam vs fire: Class A Foam for Wildland Fires. 2 ed. PMS 446-1, NFES 2246, 1993, 36p.

URBAS, Joe. Eficácia dos agentes umectantes pré-aplicados na prevenção de incêndios na interface urbana. Fogo e Materiais , v. 37, n. 8, p. 563-580, 2013.

USDA FOREST SERVICE. WFCS. DEPARTAMENT OF AGRICULTURE. Wildland Fire Chemical Products Toxicity and Environmental Concerns: General Information. 2007. Disponível em https://www.fs.fed.us/rm/fire/documents/envissu.pdf. Acesso: 13/08/2018

VOGELS, J. et al. Ecologische effecten van additieven in bluswater bij bestrijding natuurbranden. [Ecological effects of fire fighting chemicals for wildfire suppression in Dutch nature reserves]. External research report Animal Ecology, Amsterdam Global Change Institute. Driebergen:2015.

YOUNG, Ainslie T. Polymer-solvent phase separation as a route to low density, microcellular plastic foams. Journal of cellular plastics, v. 23 , n. 1, p. 55-72, 1987.

ZHANG, Xian Zhong et al. Study on the biodegradation of Class A foam by $\mathrm{CO} 2$ evolution method. In: Advanced Materials Research. Trans Tech Publications, 2012. p. 525-528. 